Check for updates

Cite this: RSC Adv., 2019, 9, 10320

Received 25th February 2019

Accepted 26th March 2019

DOI: 10.1039/c9ra01427f

rsc.li/rsc-advances

\section{Facile preparation of low-cost HKUST-1 with lattice vacancies and high-efficiency adsorption for uranium}

\begin{abstract}
Aili Yang, (D)* Ping Li and Jingrong Zhong
In this work, we prepared HKUST-1 and HKUST-1 with lattice vacancies (HLV) using benzoic acid (BA) as a lowcost modulator to replace part of the traditional trimesic acid ligand $\left(\mathrm{H}_{3} \mathrm{BTC}\right)$. The structure and morphology of the products were characterized by FTIR, XRD, SEM and XPS. The adsorption performance of the products for uranium from aqueous solutions was investigated. The results showed that the sorption of U(VI) on HKUST-1 and HLV agreed with the Langmuir isotherm model $\left(R_{\text {HKUST-1 }}{ }^{2}=0.9867\right.$ and $\left.R_{\text {HLV }}{ }^{2}=0.9828\right)$ and the maximum adsorption capacity was $430.98 \mathrm{mg} \mathrm{g}^{-1}$ and $424.88 \mathrm{mg} \mathrm{g}^{-1}$, respectively. According to kinetics studies, the adsorption fitted better with a pseudo-second-order model $\left(R_{\mathrm{HKUST-1}}{ }^{2}=1.0000\right.$ and $R_{\mathrm{HLV}}{ }^{2}=$ 0.9978). The as-prepared adsorbents were used for the removal of uranium from real water samples as well. The results showed that HLV with lower cost is a promising adsorbent for uranium from aqueous solutions.
\end{abstract}

\section{Introduction}

Nowadays, there is a growing interest in the development and applications of various nanostructured materials in many fields. ${ }^{1}$ Various materials including organic complexes, ${ }^{2}$ inorganic nanocomposites, ${ }^{3,4}$ and polyzwitterions/anions ${ }^{5}$ have been applied for contamination removal. Recently, metalorganic frameworks (MOFs) have become a new promising nanostructured material. MOFs are crystalline porous materials comprised of metal ions linked by various organic bridges. MOFs with large specific surface areas, high porosity, tuneable pore sizes and adjustable internal surfaces have been widely applied in various fields, such as gas storage and separation, ${ }^{6,7}$ catalysis, ${ }^{8,9}$ supercapacitor fabrication ${ }^{10}$ and adsorption of undesirable materials. ${ }^{11-13}$ Among various wastewater treatment technologies adsorption is considered the best and most universal technique for the removal of a wide variety of organic and inorganic pollutants..$^{14}$ Because of its excellent chemical and thermal stability, ${ }^{15,16}$ HKUST-1 is a typical material among MOFs and has been intensively investigated for the removal of various pollutants, such as $\mathrm{H}_{2} \mathrm{~S},{ }^{17} \mathrm{~Pb}(\mathrm{II}),{ }^{18}$ dyes $,{ }^{19,20} \mathrm{Sr}^{2+},{ }^{21} \mathrm{Ni}(\mathrm{II}),{ }^{22}$ $\operatorname{As}(\mathrm{v}),{ }^{23} \mathrm{Cr}(\mathrm{vI}),{ }^{24}$ hydroquinone ${ }^{25}$ fluoroquinolone, ${ }^{26}$ pesticides $^{27,28}$ and uranium. ${ }^{29,30}$

In general, trimesic acid $\left(\mathrm{H}_{3} \mathrm{BTC}\right)$ has been used as the traditional ligand to prepare HKUST-1 in the previous reports. However, the cost of $\mathrm{H}_{3} \mathrm{BTC}$ (the cost of analytical grade product is currently $566 ¥ / 500 \mathrm{~g}$ ) is much higher than that of benzoic acid (BA) with less - $\mathrm{COOH}$ groups (the cost of analytical grade product is currently $16.4 ¥ / 250 \mathrm{~g}$ ). The preparation cost of

Institute of Materials, China Academy of Engineering Physics, Huafeng Xincun No. 9 Mail-box 9071-7, Jiangyou, 621900, China. E-mail: yang770117@sina.com
HKUST-1 will greatly reduce by using BA as the ligand to replace part of $\mathrm{H}_{3}$ BTC. To the best of our knowledge, no reports have been published about the preparation and adsorption capacity of HKUST-1 using low-cost BA as the modulator for uranium from aqueous solutions. Therefore, to reduce significantly the preparation cost of HKUST-1, we used BA to replace part of the traditional $\mathrm{H}_{3} \mathrm{BTC}$ ligand to obtain HKUST-1 with lattice vacancies (HLV). Moreover, the as-synthesized HKUST-1 and HLV in the present work have another two advantages: (1) the removal rate of uranium using HKUST-1 and HLV reached 99\% even for the solutions bearing a high concentration of uranium (100 mg L $\mathrm{m}^{-1}$ ), and (2) the maximum adsorption capacity of HKUST-1 and HLV were up to about 431 and $425 \mathrm{mg} \mathrm{g}^{-1}$, respectively, which was higher than most of the reported references (see Table 3). Herein, we prepared HKUST-1 and HLV by a simple hydrothermal synthesis method for the adsorption of uranium from aqueous solutions. The influence of solution $\mathrm{pH}$, co-exiting ions, contact time, and initial $\mathrm{U}(\mathrm{vI})$ concentration on the adsorption capacity was studied. The adsorption isotherms and kinetics models were also investigated.

\section{Materials and methods}

\subsection{Materials}

Stock solutions of uranium (5-100 $\left.\mathrm{mg} \mathrm{L}^{-1}\right)$ were prepared by dissolving $\mathrm{UO}_{2}\left(\mathrm{NO}_{3}\right)_{2} \cdot 6 \mathrm{H}_{2} \mathrm{O}$ (Xi'an Dingtian Chemical Reagent Co.) in deionized water (DW) and acidified with a small amount of concentrated $\mathrm{HNO}_{3}$. All the chemicals, i.e., $\mathrm{Cu}\left(\mathrm{NO}_{3}\right)_{2} \cdot 3 \mathrm{H}_{2} \mathrm{O}$, $\mathrm{H}_{3} \mathrm{BTC}$, BA and absolute ethanol, were of analytical grade and used without further purification. DW was used throughout the experiments. 


\subsection{Preparation of HKUST-1 and HLV}

The preparation method of HKUST-1 and HLV was modified according to the ref. 31. In a typical synthesis of HKUST-1, $1.0870 \mathrm{~g}$ of $\mathrm{Cu}\left(\mathrm{NO}_{3}\right)_{2} \cdot 3 \mathrm{H}_{2} \mathrm{O}$ was dissolved in $15 \mathrm{ml} \mathrm{DW}$, while $0.5250 \mathrm{~g}$ of $\mathrm{H}_{3}$ BTC was dissolved in $15 \mathrm{ml}$ absolute ethanol. Both solutions were mixed and stirred for $30 \mathrm{~min}$. The resulting mixture was transferred into a Teflon autoclave and heated in an oven at $110{ }^{\circ} \mathrm{C}$ for $24 \mathrm{~h}$. The resultant blue crystals were filtered under vacuum and washed with ethanol and DW $(\mathrm{v}: \mathrm{v}=$ 1:1) and ethanol. Then, the products were immersed in ethanol for $36 \mathrm{~h}$ and ethanol was replaced every $12 \mathrm{~h}$. Finally, the products were filtered under vacuum and dried at $100{ }^{\circ} \mathrm{C}$ under vacuum.

In a typical synthesis of $\mathrm{HLV}, 1.0870 \mathrm{~g}$ of $\mathrm{Cu}\left(\mathrm{NO}_{3}\right)_{2} \cdot 3 \mathrm{H}_{2} \mathrm{O}$ was dissolved in $15 \mathrm{ml} \mathrm{DW}$. The mixture of $\mathrm{H}_{3}$ BTC and BA with molar ratio $3: 1$ was dissolved in $15 \mathrm{ml}$ absolute ethanol. Then, both solutions were transferred into a Teflon autoclave and heated in an oven at $110{ }^{\circ} \mathrm{C}$ for $24 \mathrm{~h}$. The resultant blue crystals were filtered under vacuum and washed with a solution of ethanol and DW (v:v=1:1) and ethanol. Then, the products were immersed in ethanol for $36 \mathrm{~h}$ and ethanol was replaced every $12 \mathrm{~h}$. Finally, the products were filtered under vacuum and dried at $100{ }^{\circ} \mathrm{C}$ under vacuum.

\subsection{Characterization of the products}

The Fourier transform infrared (FTIR) spectra of the asprepared adsorbents were obtained using an FTIR spectrometer (Bruker VERTEX 70, Germany). The crystal phases of the samples were characterized by X-ray diffraction (XRD) pattern (Dandong Fangyuan DX-2700 model, China). The surface morphology of the products was determined using scanning electron microscopy (SEM) (FEI Helios 600i, USA). X-ray photoelectron spectroscopy (XPS) was used to analysis the elemental content of HKUST-1 and HLV using an ESCALAB 250 $\mathrm{X}$-ray photoelectron spectrometer (Thermo Fisher, USA).

\subsection{Adsorption tests}

The influences of $\mathrm{pH}$, contact time and initial uranium concentration on the removal efficiency of uranium were investigated by batch adsorption experiments. The solution $\mathrm{pH}$ was adjusted by $\mathrm{NaOH}$ and $\mathrm{HCl}$. The as-prepared adsorbent was added to a $20 \mathrm{ml} \mathrm{U}$ (vi) solution and shaken in a shaker (Kangshi, China). After filtration, residual uranium concentrations were measured by a micro-quantity uranium analyser (MUA model, China). The removal rate $R(\%)$ and the adsorption capacity of $\mathrm{U}(\mathrm{vI}) Q\left(\mathrm{mg} \mathrm{g}^{-1}\right)$ were calculated according to eqn (1) and (2), respectively.

$$
\begin{gathered}
R(\%)=\frac{c_{0}-c_{t}}{c_{0}} \times 100 \\
Q\left(\mathrm{mg} \mathrm{g}^{-1}\right)=\frac{\left(c_{0}-c_{t}\right)}{W} \times V
\end{gathered}
$$

where $c_{0}\left(\mathrm{mg} \mathrm{L}^{-1}\right)$ is the initial $\mathrm{U}(\mathrm{vI})$ concentration, $c_{t}\left(\mathrm{mg} \mathrm{L}^{-1}\right)$ is $\mathrm{U}(\mathrm{vI})$ concentration at time $t, V(\mathrm{~L})$ is the solution volume and $W$ (g) is the weight of adsorbent.

\section{Results and discussion}

\subsection{Characterization of the products}

The functional group structures of HKUST-1 and HLV were determined by FTIR and are shown in Fig. 1 . The characteristic peak at $1370 \mathrm{~cm}^{-1}$ was assigned to the $\mathrm{C}-\mathrm{O}$ of $\mathrm{H}_{3} \mathrm{BTC}$, and the bands at $1448 \mathrm{~cm}^{-1}$ and $1549 \mathrm{~cm}^{-1}$ were attributed to the $\mathrm{C}=\mathrm{O}$ of $\mathrm{H}_{3}$ BTC. The characteristic peak at $1647 \mathrm{~cm}^{-1}$ resulted from aromatic $\mathrm{C}=\mathrm{C}$ of $\mathrm{H}_{3}$ BTC. This result is in accordance with a previous study. ${ }^{31,32}$ However, in the HLV FTIR spectrum, the intensity of the $\mathrm{H}_{3}$ BTC characteristic peaks at $1448 \mathrm{~cm}^{-1}$ and $1549 \mathrm{~cm}^{-1}$ attributed to $\mathrm{C}=\mathrm{O}$ and the $-\mathrm{OH}$ group at $>3000 \mathrm{~cm}^{-1}$ decreased significantly because part of the $\mathrm{H}_{3}$ BTC was replaced by BA in the HLV, which has fewer - $\mathrm{COOH}$ groups than $\mathrm{H}_{3}$ BTC. Moreover, by XPS elemental analysis the calculated atomic ratio of $\mathrm{C}: \mathrm{Cu}: \mathrm{O}$ in HKUST-1 and HLV is $8.37: 1: 4.73$ and $7.22: 1: 4.25$, respectively, which indicated that the part of $\mathrm{H}_{3} \mathrm{BTC}$ was replaced by BA with less - $\mathrm{COOH}$ groups in HLV.

The XRD patterns of the resulting HKUST- 1 and HLV are shown in Fig. 2. All of the diffraction peaks of HKUST-1 were in accordance with those reported in the ref. 29, and the indexed values of all of the diffraction peaks were accordance with the reference. ${ }^{33-35}$ Fig. 2 shows that the crystalline structure of HKUST-1 was similar to that of HLV. No obvious impurity peaks can be detected in the XRD patterns of HKUST-1 and HLV. The results showed that HKUST-1 and HLV had good chemical

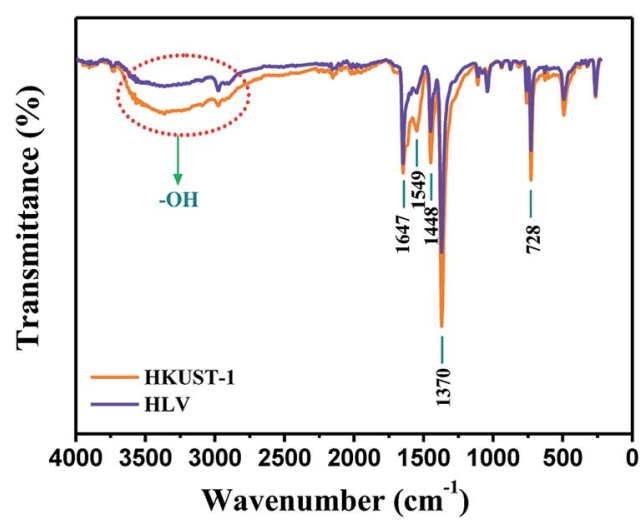

Fig. 1 FTIR spectra of HKUST-1 and HLV.

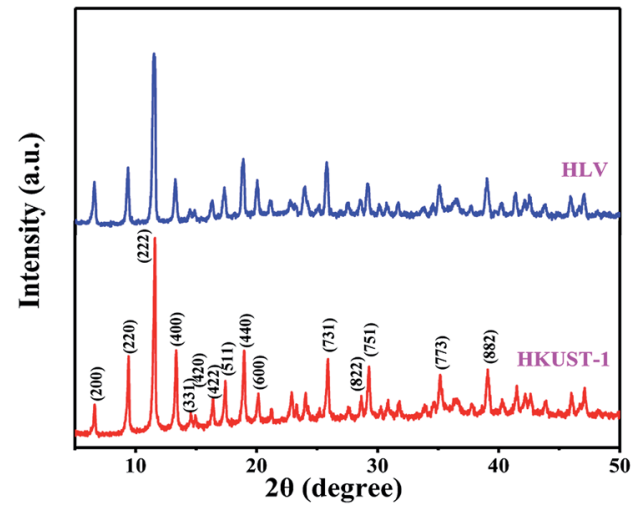

Fig. 2 XRD patterns of HKUST-1 and HLV. 
stability and high crystallinity even if the part of $\mathrm{H}_{3}$ BTC was replaced by BA. ${ }^{36}$

The morphology of HKUST-1 and HLV are shown in Fig. 3. In the SEM of HKUST-1, the crystal sizes of tens of microns (Fig. 3a) were observed. Some of the particles were octahedra with clear edges, and the other particles were flower-like (Fig. 3b). Due to the replacement by BA, the pores in HLV were deeper than those in HKUST-1.

\subsection{Effect of $\mathbf{p H}$ and co-existing ions on adsorption}

The adsorption of U(vI) by HKUST-1 and HLV as a function of $\mathrm{pH}$ was carried out over the $\mathrm{pH}$ range of 3.0-8.0 for $30 \mathrm{~min}$, as shown in Fig. 4, and the effect of co-existing ions on $\mathrm{U}(\mathrm{vI})$ adsorption was shown in Fig. 4 (inset). The results showed a significant impact of $\mathrm{pH}$ on uranium adsorption. The highest removal rate of $\mathrm{U}(\mathrm{vI})$ was observed at $\mathrm{pH} 4.0$ and was found to be nearly $100 \%$. The observed lower removal efficiency of $\mathrm{U}(\mathrm{vI})$ at $\mathrm{pH}<3$ may be attributed to formation of repulsive force between the protonated adsorbent and the positively charged uranyl ions which hindered the mass transfer and their adsorption onto the adsorbent. With the increase of $\mathrm{pH}$
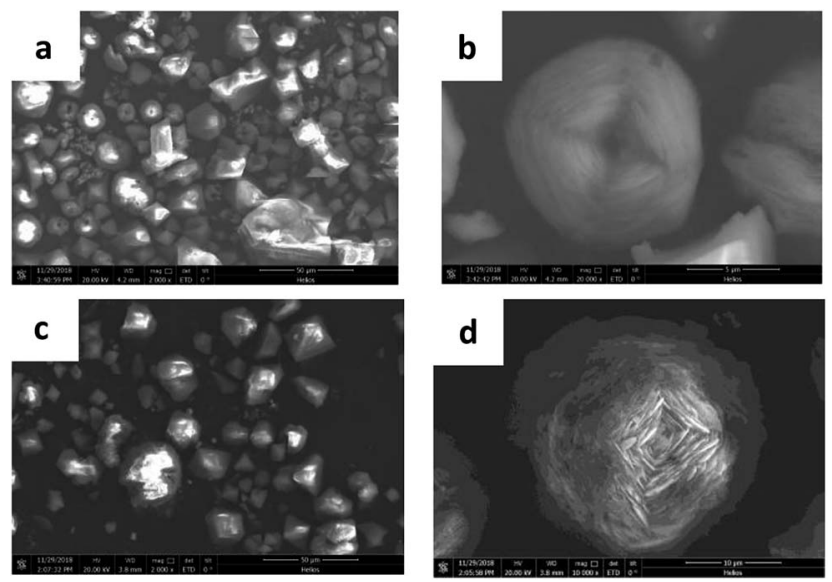

Fig. 3 SEM of HKUST-1 ((a) $2000 \times$ and (b) $20000 \times$ ) and HLV ((c) $2000 \times$ and (d) $10000 \times)$.

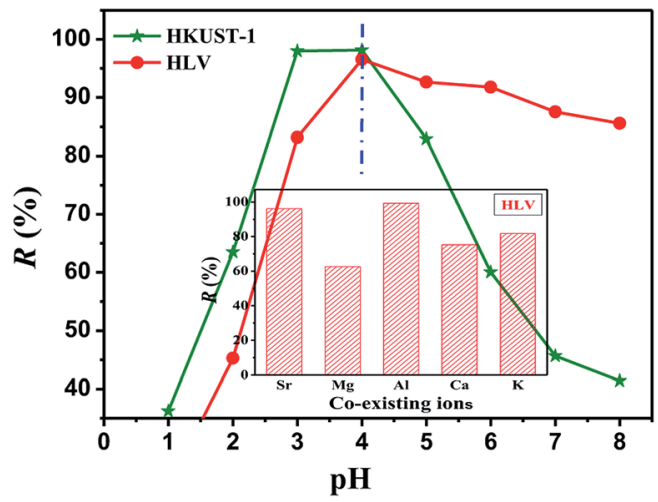

Fig. 4 Effect of $\mathrm{pH}$ on $\mathrm{U}(\mathrm{VI})$ adsorption by HKUST-1 and HLV; the inset is the effect of co-existing ions on the removal of $U(V)$ by HLV. $C_{(U) \text { initial }}$ $=10 \mathrm{mg} \mathrm{L}^{-1}, \mathrm{~m} / \mathrm{V}=0.25 \mathrm{~g} \mathrm{~L}^{-1}$, and contact time $=30 \mathrm{~min}$. deprotonation of HKUST-1 and HLV cause enhance in the complex formation and improvement in mass transfer to the adsorbent surface. ${ }^{37,38}$ However, at $\mathrm{pH}>5$ the interaction of $\mathrm{U}(\mathrm{vI})$ with HKUST-1 and HLV decreased due to the formation of uranyl species with low adsorption affinities, such as $\left[\mathrm{UO}_{2} \mathrm{OH}\right]^{+}$, $\left[\left(\mathrm{UO}_{2}\right)_{3}(\mathrm{OH})_{4}\right]^{2+},\left[\left(\mathrm{UO}_{2}\right)_{3}(\mathrm{OH})_{5}\right]^{+},\left[\left(\mathrm{UO}_{2}\right)_{2}(\mathrm{OH})_{2}\right]^{2+},\left[\left(\mathrm{UO}_{2}\right)_{2} \mathrm{OH}\right]^{3+}$, $\left[\left(\mathrm{UO}_{2}\right)_{3}(\mathrm{OH})\right]^{5+}$, and $\left[\left(\mathrm{UO}_{2}\right)_{4}(\mathrm{OH})\right]^{7+} \cdot{ }^{39}$ Therefore, the optimum pH of HKUST-1 and HLV for U(vI) adsorption was 4.0. Moreover, the effect of co-existing ions $\left(\mathrm{K}^{+}, \mathrm{Mg}^{2+}, \mathrm{Ca}^{2+}, \mathrm{Al}^{3+}\right.$ and $\left.\mathrm{Sr}^{2+}\right)$ on $\mathrm{U}(\mathrm{vI})$ sorption is examined. As shown in Fig. 4 (inset), some coexisting ions (such as $\mathrm{Mg}^{2+}$ and $\mathrm{Ca}^{2+}$ ) had significantly effect on the adsorption efficiency for U(vI) by HLV at $\mathrm{pH} 4$ while some ions (such as $\mathrm{Al}^{3+}$ and $\mathrm{Sr}^{2+}$ ) had no effect on the adsorption efficiency for $\mathrm{U}(\mathrm{VI})$.

\subsection{Influence of contact time and adsorption kinetics study}

Fig. 5a shows the effect of contact time on uranium adsorption by HKUST-1 and HLV. The adsorption efficiency of HKUST-1
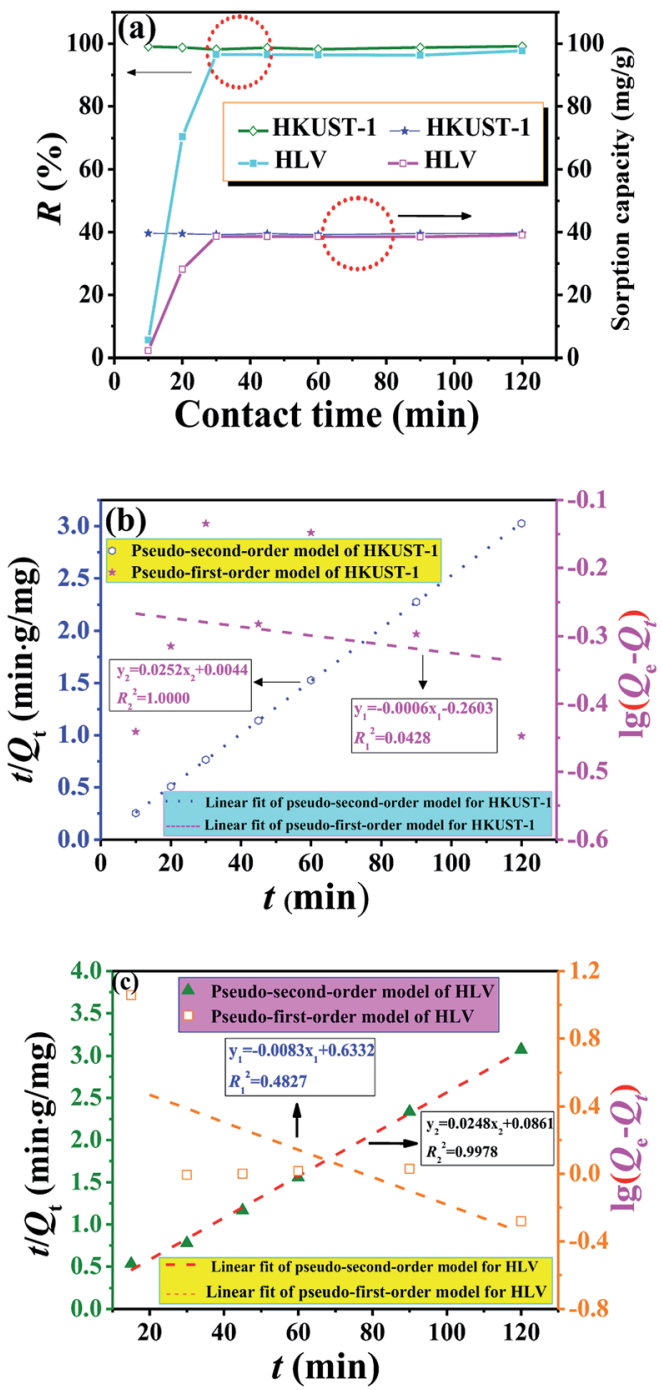

Fig. 5 (a) Influence of contact time on $U(\mathrm{vl})$ adsorption, (b) kinetics model fits of HKUST-1 and (c) kinetics model fits of HLV. $\mathrm{pH}=4.0, C_{(U) \text { initial }}=10 \mathrm{mg} \mathrm{L}^{-1}$, and $\mathrm{m} / \mathrm{V}=0.25 \mathrm{~g} \mathrm{~L}^{-1}$. 


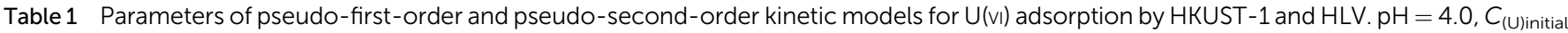
$=10 \mathrm{mg} \mathrm{L}^{-1}, \mathrm{~m} / \mathrm{V}=0.25 \mathrm{~g} \mathrm{~L}^{-1}$

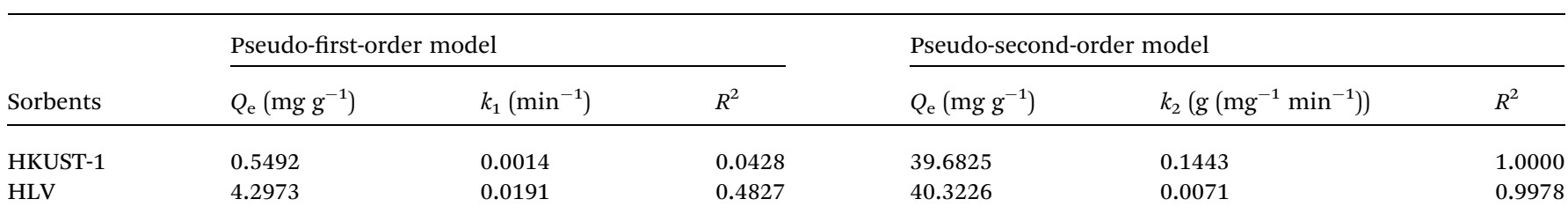

and HLV improved significantly with time and reached adsorption equilibrium within $30 \mathrm{~min}$. The removal rates of uranium of HKUST- 1 and HLV were up to $\sim 99 \%$. The linear fit of pseudo-first-order and pseudo-second-order kinetic models for U(vI) adsorption by HKUST-1 and HLV is shown in Fig. $5 b$ and c, and the calculated fit parameters according to eqn (3) and (4) ${ }^{40}$ are given in Table 1 . The correlation coefficient of the pseudo-second-order model $\left(R^{2}=1.0000\right.$ for HKUST- 1 and $R^{2}=$ 0.9978 for HLV) was superior to that of the pseudo-first-order model, which indicated that the adsorption of $\mathrm{U}(\mathrm{vI})$ onto HKUST-1 and HLV fit the pseudo-second-order model well. The fit results demonstrated that the chemical interactions played a significant role in the rate-controlling steps. The equations are as follows:

$$
\begin{gathered}
\lg \left(Q_{\mathrm{e}}-Q_{t}\right)=\lg Q_{\mathrm{e}}-\frac{k_{1}}{2.303} t \\
\frac{t}{Q}=\frac{1}{k_{2} Q_{\mathrm{e}}{ }^{2}}+\frac{t}{Q_{\mathrm{e}}}
\end{gathered}
$$

where $k_{1}\left(\mathrm{~min}^{-1}\right)$ is the Lagergren rate constant of adsorption and $k_{2}\left(\mathrm{~g}\left(\mathrm{mg}^{-1} \mathrm{~min}^{-1}\right)\right)$ is the rate constant of pseudo-secondorder adsorption.

\subsection{Adsorption isotherm}

The Langmuir and Freundlich isotherm models are expressed in eqn (5) and (6), ${ }^{40}$ respectively, and the calculated Langmuir and Freundlich isotherm fit data of HKUST-1 and HLV are shown in Table 2. It is clear from Fig. 6 that the equilibrium adsorption for HKUST-1 and HLV fit well to the Langmuir model, and the correlation coefficients of HKUST-1 and HLV were 0.9867 and 0.9828 , respectively. The maximum adsorption capacity $\left(Q_{\mathrm{m}}\right)$ of HKUST-1 and HLV for U(vI) reached $430.98 \mathrm{mg}$ $\mathrm{g}^{-1}$ and $424.88 \mathrm{mg} \mathrm{g}^{-1}$, respectively. Though HLV has more lattice vacancies than that of HKUST-1 because of the replacement by BA, the $Q_{\mathrm{m}}$ of HKUST-1 was higher than that of HLV, which showed that the adsorption mechanism was mainly the surface complexion and not the increase of active sites.

$$
\begin{aligned}
Q_{\mathrm{e}} & =\frac{Q_{\mathrm{m}} K_{\mathrm{L}} C_{\mathrm{e}}}{1+K_{\mathrm{L}} C_{\mathrm{e}}} \\
Q_{\mathrm{e}} & =K_{\mathrm{F}} C_{\mathrm{e}}^{1 / n}
\end{aligned}
$$

where $Q_{\mathrm{e}}\left(\mathrm{mg} \mathrm{g}^{-1}\right)$ is the equilibrium adsorption capacity, $C_{\mathrm{e}}$ $\left(\mathrm{mg} \mathrm{L}^{-1}\right)$ is the uranium concentration at equilibrium, $Q_{\mathrm{m}}(\mathrm{mg}$ $\left.\mathrm{g}^{-1}\right)$ is the maximum adsorption capacity, $K_{\mathrm{L}}\left(\mathrm{L} \mathrm{mg}^{-1}\right)$ and $K_{\mathrm{F}}$ $\left(\mathrm{mg}^{1-n} \mathrm{~L}^{n} \mathrm{~g}^{-1}\right)$ are the Langmuir constant and Freundlich constant, respectively, and $n$ is the Freundlich adsorption exponent.

A comparison of $Q_{\mathrm{m}}$ of HKUST-1 and HLV in this work and the reported other adsorbents is presented in Table 3. Table 3 shows that as-prepared low-cost HLV had higher $Q_{\mathrm{m}}$ than most of the reported adsorbents and proved to be a promising adsorbent for the treatment of uranium-bearing wastewater.

\subsection{Adsorption efficiency for real wastewater samples}

Under the optimum adsorption conditions, the removal efficiency of U(vI) by HKUST-1 and HLV for low-level uranium-

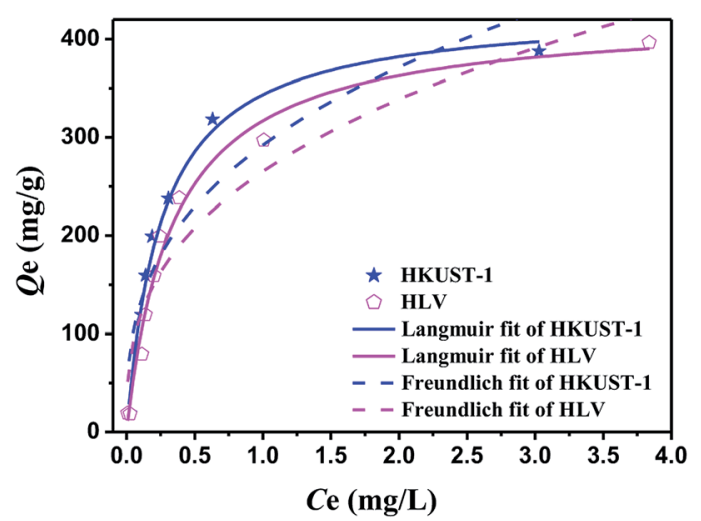

Fig. 6 Linear fit of Langmuir and Freundlich isotherm models of HKUST-1 and HLV. $\mathrm{pH}=4.0, \mathrm{C}_{(\mathrm{U}) \text { initial }}=5-100 \mathrm{mg} \mathrm{L}^{-1}, \mathrm{~m} / \mathrm{V}=0.25 \mathrm{~g}$

\begin{tabular}{|c|c|c|c|c|c|c|}
\hline Sorbents & \multicolumn{3}{|c|}{ Langmuir model } & \multicolumn{3}{|c|}{ Freundlich model } \\
\hline HLV & 424.88 & 2.9348 & 0.9828 & 2.84 & 265.30 & 0.8972 \\
\hline
\end{tabular}
$\mathrm{L}^{-1}$, and contact time $=24 \mathrm{~h}$.

Table 2 Langmuir and Freundlich model parameters for uranium adsorption on HKUST-1 and HLV. pH $=4.0, C_{(U) \text { initial }}=10 \mathrm{mg} \mathrm{L}{ }^{-1}, m / V=0.25 \mathrm{~g}$ $\mathrm{L}^{-1}$ and contact time $=24 \mathrm{~h}$ 
Table 3 Maximum adsorption capacity of various adsorbents for $U(V)$ ions

\begin{tabular}{|c|c|c|c|c|}
\hline Sorbents & $\mathrm{pH}$ & $m / V\left(\mathrm{~g} \mathrm{~L}^{-1}\right)$ & $Q_{\mathrm{m}}\left(\mathrm{mg} \mathrm{g}^{-1}\right)$ & References \\
\hline Modified aluminosilica & 3.5 & 1.0 & 83.30 & 39 \\
\hline Modified red muds & 3.0 & 3.5 & 124.56 & 41 \\
\hline MNPs@PAO & 6.0 & 0.5 & 216.45 & 43 \\
\hline Polypyrrole & 5.0 & 1.0 & 87.72 & 44 \\
\hline Pseudomonas monteilii & 6.0 & 0.3 & 267.30 & 45 \\
\hline HKUST-1 & 6.0 & 0.4 & 787.40 & 29 \\
\hline HKUST-1@ $\mathrm{H}_{3} \mathrm{PW}_{12} \mathrm{O}_{40}$ & 6.0 & 0.2 & 14.58 & 30 \\
\hline HKUST-1 & 4.0 & 0.25 & 430.98 & This work \\
\hline HLV & 4.0 & 0.25 & 424.88 & This work \\
\hline
\end{tabular}

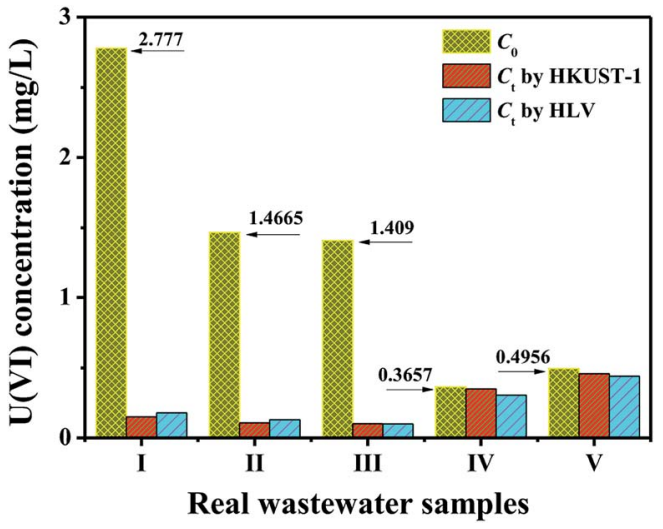

Fig. 7 Column chart of the adsorption efficiency of HKUST-1 and HLV for real uranium-bearing nuclear waste effluents. $\mathrm{pH}=4.0, \mathrm{C}_{(\mathrm{U}) \text { initial }}=$ $0.3-3.0 \mathrm{mg} \mathrm{L}^{-1}, \mathrm{~m} / \mathrm{V}=0.25 \mathrm{~g} \mathrm{~L}^{-1}$, and contact time $=30 \mathrm{~min}$.

bearing real wastewater from five different batches was evaluated. Some micro-quantity metal ions (e.g., $\mathrm{Al}, \mathrm{B}, \mathrm{Ca}, \mathrm{Be}, \mathrm{Fe}, \mathrm{Cu}$, $\mathrm{Mn}, \mathrm{Mg}, \mathrm{Si}, \mathrm{Ni}$ and $\mathrm{Mo}$ ) were found to exist in the real wastewater samples. All elements in real samples were analyzed by inductively coupled plasma-atomic emission spectrometry (ICPAES) (Thermo Fisher iCAP 6300, USA). The adsorption experiments results are presented in Fig. 7. As shown in Fig. 7, HKUST-1 and HLV had favourable adsorption capacity for highlevel uranium-bearing wastewater $\left(>1.0 \mathrm{mg} \mathrm{L}^{-1}\right)$, and the coexisting ions had no effect on the removal efficiency for uranium. However, the uranium concentration after treatment with HKUST-1 and HLV was not significantly reduced when the uranium concentration was very low.

\section{Conclusions}

In this work, HKUST-1 and HLV were synthesized in a facile manner by hydrothermal methods and exhibited high-efficiency adsorption capacity for uranium from aqueous solutions, especially high-level uranium-containing wastewater. The optimal adsorption conditions included a $\mathrm{pH}$ of $4.0,0.25 \mathrm{~g} \mathrm{~L}^{-1}$ of adsorbent dose and $30 \mathrm{~min}$ of contact time when the initial uranium concentration was $10 \mathrm{mg} \mathrm{L}^{-1}$. The effect of co-existing ions $\left(\mathrm{K}^{+}, \mathrm{Mg}^{2+}, \mathrm{Ca}^{2+}, \mathrm{Al}^{3+}\right.$ and $\left.\mathrm{Sr}^{2+}\right)$ on the uranium removal by HLV was studied. Results showed that some co-existing ions (such as $\mathrm{Mg}^{2+}$ and $\mathrm{Ca}^{2+}$ ) had significantly effect on the adsorption efficiency for $\mathrm{U}(\mathrm{vI})$ by HLV at $\mathrm{pH} 4$ while some ions (such as $\mathrm{Al}^{3+}$ and $\mathrm{Sr}^{2+}$ ) had no effect on the adsorption efficiency for $\mathrm{U}(\mathrm{vI})$. The adsorption processes of HKUST-1 and HLV were well described by the Langmuir isotherm model and pseudo-secondorder kinetic model. The maximum adsorption capacities of HKUST-1 and HLV were 430.98 and $424.88 \mathrm{mg} \mathrm{g}^{-1}$, respectively, which is much higher than that of other reported adsorbents. Moreover, HKUST-1 and HLV exhibited favorable adsorption performance for real $\mathrm{U}(\mathrm{vI})$-bearing wastewater samples in practical application. Compared with HKUST-1, low-cost HLV is a very promising potential adsorbent for the removal of uranium from aqueous solutions.

\section{Conflicts of interest}

There are no conflicts to declare.

\section{Acknowledgements}

This work is financially supported by National Natural Science Foundation of China (21407132) and Environmental Protection Foundation of China Academy of Engineering Physics (YAHZY2018-008).

\section{References}

1 A. M. Alansi, W. Z. Alkayali, M. H. Al-qunaibit, T. F. Qahtan and T. A. Saleh, RSC Adv., 2015, 5(87), 71441-71448.

2 R. Soury, M. Jabli, T. A. Saleh, W. S. Abdul-Hassan, E. SaintAman, F. Loiseau, C. Philouze and H. Nasri, RSC Adv., 2018, 8(36), 20143-20156.

3 M. M. Al-Shalalfeh, T. A. Saleh and A. A. Al-Saadi, RSC Adv., 2016, 6(79), 75282-75292.

4 H. A. Sani, M. B. Ahmad and T. A. Saleh, RSC Adv., 2016, 6(110), 108819-108827.

5 Z. A. Jamiu, T. A. Saleh and S. A. Ali, $R S C A d v$., 2015, 5(53), 42222-42232. 
6 J. M. Yu, L. H. Xie, J. R. Li, Y. G. Ma, J. M. Seminario and P. B. Balbuena, Chem. Rev., 2017, 117, 9674-9754.

7 K. Xie, Q. Fu, C. L. Xu, H. Lu, Q. H. Zhao, R. Curtain, D. Y. Gu, P. A. Webley and G. G. Qiao, Energy Environ. Sci., 2018, 11, 544-550.

8 R. V. Jagadeesh, K. Murugesan, A. S. Alshammari, H. Neumann, M. M. Pohl, J. Radnik and M. Beller, Science, 2017, 358, 326-332.

9 M. M. Wan, X. L. Zhang, M. Y. Li, B. Chen, J. Yin, H. C. Jin, L. Lin, C. Chen and N. Zhang, Small, 2017, 13, 1701395.

10 D. Sheberla, J. C. Bachman, J. S. Elias, C. J. Sun, Y. Shao-Horn and M. Dincă, Nat. Mater., 2017, 16, 220-225.

11 Y. H. Pi, X. Y. Li, Q. B. Xia, J. L. Wu, Y. W. Li, J. Xiao and Z. Li, Chem. Eng. J., 2018, 337, 351-371.

12 N. A. A. Qasem, R. Ben-Mansour and M. A. Habib, Appl. Energy, 2018, 210, 317-326.

13 D. Bahamon, A. Díaz-Márquez, P. Gamallo and L. F. Vega, Chem. Eng. J., 2018, 342, 458-473.

14 V. K. Gupta, I. Ali, T. A. Saleh, A. Nayak and S. Agarwal, RSC $A d v .$, 2012, 2(16), 6380-6388.

15 L. H. Wee, M. R. Lohe, N. Janssens, S. Kaskel and J. A. Martens, J. Mater. Chem., 2012, 22, 13742-13746.

16 C. Volkringer, C. Falaise, P. Devaux, R. Giovine, V. Stevenson, F. Pourpoint, O. Lafon, M. Osmond, C. Jeanjacques, B. Marcillaud, J. C. Sabroux and T. Loiseau, Chem. Commun., 2016, 52, 12502-12505.

17 H. Y. Zhang, Z. R. Zhang, C. Yang, L. X. Ling, B. J. Wang and H. L. Fan, J. Inorg. Organomet. Polym. Mater., 2018, 28, 694701.

18 W. X. Yang, J. Wang, Q. F. Yang, H. N. Pei, N. Hu, Y. R. Suo, Z. H. Li, D. H. Zhang and J. L. Wang, Chem. Eng. J., 2018, 339, 230-239.

19 H. M. Abd El Salam and T. Zaki, Inorg. Chim. Acta, 2018, 471, 203-210.

20 N. Chen, N. D. Chen, F. H. Wei, S. Q. Zhao and Y. Luo, Chem. Phys. Lett., 2018, 705, 23-30.

21 S. Yekta and M. J. Sadeghi, J. Inorg. Organomet. Polym. Mater., 2018, 28, 1049-1064.

22 M. R. Faradonbeh, A. A. Dadkhah, A. Rashidi, S. Tasharofi and F. Mansourkhani, J. Inorg. Organomet. Polym. Mater., 2018, 28, 829-836.

23 C. Zhang, Y. Xiao, Y. Qin, Q. C. Sun and S. H. Zhang, J. Solid State Chem., 2018, 261, 22-30.

24 S. B. Wu, Y. J. Ge, Y. Q. Wang, X. Chen, F. F. Li, H. Xuan and X. Li, Environ. Technol., 2018, 39, 1937-1948.

25 G. P. Li, S. L. Pang, Y. W. Wu and J. Ouyang, Chem. Eng. Commun., 2018, 205, 698-705.
26 G. Wu, J. P. Ma, S. Li, J. Guan, B. Jiang, L. Y. Wang, J. H. Li, X. Y. Wang and L. X. Chen, J. Colloid Interface Sci., 2018, 528, 360-371.

27 J. P. Ma, G. Wu, S. Li, W. Q. Tan, X. Y. Wang, J. H. Li and L. X. Chen, J. Chromatogr. A, 2018, 1553, 57-66.

28 J. P. Ma, Z. D. Yao, L. W. Hou, W. H. Lu, Q. P. Yang, J. H. Li and L. X. Chen, Talanta, 2016, 161, 686-692.

29 Y. F. Feng, H. Jiang, S. N. Li, J. Wang, X. Y. Jing, Y. R. Wang and M. Chen, Colloids Surf., A, 2013, 431, 87-92.

30 H. Zhang, J. H. Xue, N. Hu, J. Sun, D. X. Ding, Y. D. Wang and L. Li, J. Radioanal. Nucl. Chem., 2017, 308, 865-875.

31 M. R. Azhar, H. R. Abid, H. Q. Sun, V. Periasamy, M. O. Tadé and S. B. Wang, J. Colloid Interface Sci., 2016, 478, 344-352.

32 K.-Y. A. Lin and Y.-T. Hsieh, J. Taiwan Inst. Chem. Eng., 2015, 50, 223-228.

33 Z. Q. Li, L. G. Qiu, T. Xu, Y. Wu, W. Wang, Z. Y. Wu and X. Jiang, Mater. Lett., 2009, 63, 78-80.

34 T. A. Saleh, Nanomaterial and polymer membranes, Elsevier, 2016, ISBN-13: 978-0128047033.

35 T. A. Saleh, Advanced nanomaterials for water engineering, treatment, and hydraulics, IGI Glob., 2017, ISBN-13: 9781522521365.

36 A. W. Thornton, R. Babarao, A. Jain, F. Trousselet and F.-X. Coudert, Dalton Trans., 2015, 45, 4352-4359.

37 F. Zare, M. Ghaedi, A. Daneshfar, S. Agarwal, I. Tyagi, T. A. Saleh and V. K. Gupta, Chem. Eng. J., 2015, 273, 296306.

38 T. A. Saleh, K. Naeemullah, M. Tuzen and A. Sarı, Chem. Eng. Res. Des., 2017, 117, 218-227.

39 E. A. Elshehy, Sep. Sci. Technol., 2017, 52, 1852-1861.

40 X. Guo, Y. R. Feng, L. Ma, D. Z. Gao, J. Jing, J. C. Yu, H. B. Sun, H. Y. Gong and Y. J. Zhang, Appl. Surf. Sci., 2017, 402, 53-60.

41 W. Y. Wu, D. Y. Chen, J. W. Li, M. H. Su and N. Chen, Environ. Sci. Pollut. Res., 2018, 25, 18096-18108.

42 R. Khamirchi, A. Hosseini-Bandegharaei, A. Alahabadi, S. Sivamani, A. Rahmani-Sani, T. Shahryari, I. Anastopoulos, M. Miri and H. N. Tran, Ecotoxicol. Environ. Saf., 2018, 150, 136-143.

43 Z. R. Dai, H. Zhang, Y. Sui, D. X. Ding, N. Hu, L. Li and Y. D. Wang, J. Radioanal. Nucl. Chem., 2018, 316, 369-382.

44 S. Abdi, M. Nasiri, A. Mesbahi and M. H. Khani, J. Hazard. Mater., 2017, 332, 132-139.

45 X. Y. Deng, Y. L. Feng, H. R. Li, F. Yuan, Q. Teng and H. J. Wang, J. Radioanal. Nucl. Chem., 2018, 315, 243-250.

46 J. L. Wu, K. Tian and J. L. Wang, Prog. Nucl. Energy, 2018, 106, 79-86.

47 J. Tan, Y. F. Wang, N. Liu and M. W. Liu, J. Radioanal. Nucl. Chem., 2018, 315, 119-126. 